\title{
Multistage Stochastic Programming via Autoregressive Sequences ${ }^{\#}$
}

\author{
Vlasta Kan̆ková*
}

\section{Introduction}

Multistage stochastic programming problems belong to optimization problems depending on a probability measure. Usually, the operator of mathematical expectation appears in an objective function and, moreover, constraints set can depend on the probability measure also. The multistage stochastic programming problems correspond to applications (with an unneglected random element) that can be reasonably considered with respect to some finite "discrete" (say $(1, M) ; M \geq 2$ ) time interval and simultaneously there exists a possibility to decompose them with respect to the individual time points. Moreover, a decision, at every individual time point say $k$, can depend only on the random elements realizations and the decisions to the time point $k-1$ (we say that it must be nonanticipative).

Many applications of the multistage stochastic programs are known from the literature. Let us recall some of them: Financial problems (see e.g. Dupačová - Hurt Štěpán, 2002; Frauendorfer - Schürle, 2000), melt control problem (see e.g. Dupačová - Hurt - Štěpán, 2002; Dupačová - Popela, 2005), power-station planning (see e.g. Kuhn, 2005), power scheduling and hydro-thermal system control (see e.g. Nowak Römisch, 2000), energy problems (see e.g. Wallace - Fleten, 2003), transportation and logistics problems (see e.g Powel - Topaglu, 2003), unemployment problem (see e.g. Chovanec, 2004; Kaňková - Chovanec, 2006). Some others can be found e.g. in King (1988) and Prékopa (1995).

Evidently, to solve the multistage stochastic programs (generally) a complete information on the "underlying" probability measure is necessary. However, this assumption is fulfilled in real-life situation very seldom. An approximate probability measure (caused e.g. by a contamination) is only known in many cases. Very often also only some data are available instead of the "underlying" probability measure. According to this fact, the stability (considered with respect to the probability measures space) has been investigated in the stochastic programming literature many times. Moreover, the stability properties are also very important for a construction of approximate solution schemes.

In the paper, we focus on the analysis of the multistage stochastic programming problems in which the random element follows an autoregressive sequence and the constraints sets correspond to the individual probability constraints. It is known, that just a development of many economic characteristics follows autoregressive sequences

This research was supported by the Grant Agency of the Czech Republic under Grants 402/07/1113, 402/06/0990 and 402/03/H057.

RNDr. Vlasta Kaňková, CSc. - research fellow; Department of Econometrics, Institute of Information Theory and Automation of the Academy of Sciences of the Czech Republic, Pod vodárenskou věži 4, 18208 Prague 8, Czech Republic; <kankova@utia.cas.cz>. 
(see e.g. in the financial mathematics the development of the price of market index or the price of bonds). From the mathematical point of view, this type of the development of the random characteristics gives a possibility to obtain suitable properties of the individual decomposed problems.

In spite of the fact that many applications of the multistage problems can be found in the literature, this type of the problems belongs (from the numerical point of view) to very complicated ones. They can practically be solved only approximately. In the literature, there were introduced some approximation methods solution. We can recall multistage version of the Bender's algorithm (see e.g. Dupačová - Hurt - Štěpán, 2002), a scenario approach based on the Barycentric approximation (see e.g. Kuhn, 2005), aggregation technique (see e.g. Birge - Louveaux, 1997), a discretization based on the stability results (see e.g. Kaňková - Šmíd, 2004; Pflug, 2001; Šmíd, 2004), L shaped decomposition algorithm (see e.g. Ruszcyński, 2003). Some others can be found in Ermoliev - Wets (1988), Wallace - Ziemba (2005). According to the difficulties of the problem, the introduced models have been mostly linear with "deterministic" constraints sets. We shall deal with the nonlinear model with the individual probability constraints. Obviously, this case can cover more applications. However, we consider the assumptions under which the considered problems can be transformed to the "classical" (generally) nonlinear case with constraints sets given by a system of algebraic inequalities. Moreover, we shall mention the assumptions under which the multistage problem can be decomposed to the system of one-stage parametric problems.

Similar problems with the Markov type of dependence have been investigated in Kaňková - Šmíd (2004) and Kaňková (2005). However, this paper tries to present more detailed analysis of the problem and, moreover, the stability bounds (suggested on the base of this paper) can be acceptable from the numerical point of view.

\section{Mathematical Definition and Analysis}

A general $M$-stage $(M \geq 2)$ stochastic programming problem can be introduced as an optimization problem with respect to some mathematical abstract space (say $L_{p}$ space, $p \geq 1$ ) or recursively as a system of parametric optimization problems (considered with respect to the Euclidean space) with an inner type of dependence and mathematical (mostly conditional) expectation in the objective functions of the individual problems. The constraints sets can be determined by multifunctions depending on the "underlying" probability measure.

It is known that (generally) the above mentioned two definitions of the multistage stochastic programming problem are not equivalent. Some assumptions (under which) the existence of the problem solution considered with respect to one definition guarantees the existence of the problem solution, considered with respect to the next definition, are introduced in Kuhn, (2005). Moreover, then the both optimal values are the same. To this end, crucial assumptions are: "deterministic" (not depending on the probability measure) constraints sets, a random element following an autoregressive random sequence, $L_{p}$ space considered for $p=+\infty$ and an additive form of the objective functions. 
To introduce the mathematical definition of the multistage stochastic programming problem we employ a recursive approach. To this end let $\xi^{j}, j=1, \ldots, M$ denote an $s$-dimensional random vector; $F^{\xi^{j}}\left(z^{j}\right), \quad z^{j} \in R^{s}, j=1,2, \ldots, M$ denote the distribution function of the $\xi^{j}$ and $F^{\xi^{k} \mid \bar{\xi}^{k-1}}\left(z^{k} \mid \bar{z}^{k-1}\right)$, $z^{k} \in R^{s}, \bar{z}^{k-1} \in R^{(k-1) s}, k=2, \ldots, M$ denote the conditional distribution function $\left(\xi^{k}\right.$ conditioned by $\left.\bar{\xi}^{k-1}\right) ; \bar{\xi}^{k}=\left[\xi^{1}, \ldots, \xi^{k}\right], \bar{z}^{k}=\left[z^{1}, \ldots, z^{k}\right], z^{j} \in R^{s}$.

Let, furthermore, $g_{0}^{M}\left(\bar{x}^{M}, \bar{z}^{M}\right)$ be a continuous function defined on $R^{n M} \times R^{s M}$; $X^{k} \subset R^{n}, \quad k=1,2, \ldots, M$ be a nonempty set; $K_{F}^{k+1}\left(\bar{x}^{k}, \bar{z}^{k}\right), \quad k=1, \ldots, M-1$ be a multifunction mapping $R^{n k} \times R^{s k}$ into the space of subsets of $R^{n} \cdot \bar{x}^{k}=\left[x^{1}, \ldots, x^{k}\right]$, $x^{j} \in R^{n}, \quad j=1, \ldots, k, \quad \bar{X}^{k}=X^{1} \times X^{2} \ldots \times X^{k}, \quad k=1,2, \ldots, M . \quad\left(R^{n}, n \geq 1\right.$ denotes an $n$-dimensional Euclidean space.)

A general $M$-stage stochastic programming problem $(M \geq 2)$ can be then introduced (see e.g. Birge (1988); Dupačová (1995); Kaňková (2007); Kuhn (2005) or Prékopa (1995)) in the form:

Find

$$
\varphi(F)=\inf \left\{\mathrm{E}_{F^{\xi^{1}}} g_{F}^{1}\left(x^{1}, \xi^{1}\right) \mid x^{1} \in X^{1}\right\}
$$

where the function $g_{F}^{1}\left(x^{1}, z^{1}\right)$ is defined recursively

$$
\begin{aligned}
& g_{F}^{k}\left(\bar{x}^{k}, \bar{z}^{k}\right) \quad=\inf \left\{\mathrm{E}_{F^{\xi^{k+1} \bar{\xi}^{k}=\bar{z}^{k}}} g_{F}^{k+1}\left(\bar{x}^{k+1}, \bar{\xi}^{k+1}\right) \mid x^{k+1} \in K_{F}^{k+1}\left(\bar{x}^{k}, \bar{z}^{k}\right)\right\}, \\
& k=1, \ldots, M-1, \\
& g_{F}^{M}\left(\bar{x}^{M}, \bar{z}^{M}\right):=g_{0}^{M}\left(\bar{x}^{M}, \bar{z}^{M}\right) .
\end{aligned}
$$

$\mathrm{E}_{F^{\xi^{1}}}, \mathrm{E}_{F^{\xi^{k+1} \mid \bar{\xi}^{k}=\bar{z}^{k}}}, k=1, \ldots, M-1$ denote the operators of mathematical expectation corresponding to $F^{\xi^{1}}(\cdot), F^{\xi^{k+1} \mid \bar{\xi}^{k}}\left(\cdot \mid \bar{z}^{k}\right)$. The multifunctions $K_{F}^{k+1}\left(\bar{x}^{k}, \bar{z}^{k}\right)$ are supposed to be depending on the conditional probability measure,

$$
K_{F}^{k+1}\left(\bar{x}^{k}, \bar{z}^{k}\right)=K_{F^{\xi^{k+1} \mid \bar{\xi}^{k}}}^{k+1}\left(\bar{x}^{k}, \bar{z}^{k}\right), \quad k=1, \ldots, M-1 .
$$

Evidently, the "underlying" random element is completely determined by the system of the conditional probability distribution functions

$$
F=\left\{F^{\xi^{1}}\left(z^{1}\right), \quad F^{\xi^{k} \mid \bar{\xi}^{k-1}}\left(z^{k} \mid \bar{z}^{k-1}\right), k=2, \ldots, M\right\} .
$$

In this paper, we consider the multifunctions $K_{F}^{k+1}\left(\bar{x}^{k}, \bar{z}^{k}\right), k=1, \ldots, M-1$ in a rather special case when there exist $g_{i}^{k+1}\left(\bar{x}^{k+1}\right), i=1,2 \ldots, s, \quad k=1,2, \ldots, M-1$ defined on $R^{n(k+1)}$ and $\alpha_{i} \in(0,1), i=1, \ldots, s, \bar{\alpha}=\left(\alpha_{1}, \ldots, \alpha_{s}\right)$ such that 


$$
\begin{aligned}
& K_{F}^{k+1}\left(\bar{x}^{k}, \bar{z}^{k}\right)\left(:=K_{F}^{k+1}\left(\bar{x}^{k}, \bar{z}^{k} ; \bar{\alpha}\right)\right)= \\
& \bigcap_{i=1}^{s}\left\{x^{k+1} \in X^{k+1}: P_{F^{\xi^{k+1} \bar{\xi}_{i=}^{k}} k}\left\{g_{i}^{k+1}\left(\bar{x}^{k+1}\right) \leq \xi_{i}^{k+1}\right\} \geq \alpha_{i}\right\}, \xi^{k+1}=\left(\xi_{1}^{k+1}, \ldots, \xi_{s}^{k+1}\right)
\end{aligned}
$$

and, moreover, when the following assumption A.1 is fulfilled

A.1 $\left\{\xi^{k}\right\}_{k=-\infty}^{\infty}$ follows a nonlinear autoregressive sequence

$$
\xi^{k}=H\left(\xi^{k-1}\right)+\varepsilon^{k}
$$

where $\xi^{1}, \varepsilon^{k}, \quad k=1,2, \ldots$ are stochastically independent $\left(\varepsilon^{k}=\left(\varepsilon_{1}^{k}, \ldots, \varepsilon_{s}^{k}\right)\right.$, $k=1, \ldots$ identically distributed), $H(z)$ is an $s$-dimensional Lipschitz vector function, $H=\left(H_{1}, \ldots, H_{s}\right)$ defined on $R^{s}$. We denote the distribution function corresponding to $\varepsilon^{1}$ by $F^{\varepsilon}$.

Furthermore, if we define in this case

$$
\begin{aligned}
k_{F_{i}^{\left.\xi^{k}\right|_{\xi} ^{k-1}}}\left(\alpha_{i}\right) & \left.=\sup _{z_{i}^{k}} P_{F_{i}^{\left.\xi^{k}\right|_{\xi} ^{k-1}}}\left\{z_{i}^{k} \leq \xi_{i}^{k}\right\} \geq \alpha_{i}\right\}, \quad k=1, \ldots, M, \\
k_{F_{i}^{\varepsilon}}\left(\alpha_{i}\right) & \left.=\sup _{z_{i}} P_{F_{i}^{\varepsilon}}\left\{z_{i} \leq \varepsilon_{i}\right\} \geq \alpha_{i}\right\},
\end{aligned}
$$

then $k_{F_{i}^{\varepsilon}}\left(\alpha_{i}\right)=k_{F_{i}^{\xi^{k}||^{k-1}}}\left(\alpha_{i}\right)-H_{i}\left(\xi^{k-1}\right) ; F_{i}^{\varepsilon}, i=1, \ldots, s$ are one dimensional marginal distribution functions corresponding to $F^{\varepsilon}$. According to the relation (4) and the assumption A. 1 we can obtain for $k=1, \ldots, M-1$ that

$$
K_{F}^{k+1}\left(\bar{x}^{k}, \bar{\xi}^{k}\right)=\bigcap_{i=1}^{s}\left\{x^{k+1} \in X^{k+1}: g_{i}^{k+1}\left(\bar{x}^{k+1}\right) \leq k_{F_{i}^{\varepsilon}}\left(\alpha_{i}\right)+H_{i}\left(\xi^{k}\right)\right\} .
$$

The multifunctions $K_{F}^{k+1}\left(\bar{x}^{k}, \bar{\xi}^{k}\right), k=1, \ldots, M-1$ are (under the assumption A.1) determined by a system of algebraic inequalities. The problem introduced by (1), (2) and (4) is then equivalent to the "classical" multistage stochastic programming problem. However, since the constraints sets $K_{F}^{k+1}\left(\bar{x}^{k}, \bar{z}^{k}\right)$ are practically determined by the quantiles $k_{F_{i}^{\varepsilon}}\left(\alpha_{i}\right), i=1, \ldots, s$, new difficulties can arise everywhere, when the distribution function $F^{\varepsilon}$ is not completely known. Some difficulties can also arise by a construction of the approximate solution schemes. We have to be (in the above mentioned case) very careful. A small change on the right hand side of (5) can rapidly change the probability of constraints fulfilling.

The objective functions of the decomposed problems in (1), (2)

$$
\begin{gathered}
g_{F}^{k}\left(\bar{x}^{k}, \bar{z}^{k}\right)=\inf \left\{\mathrm{E}_{F^{\xi^{k+1} \mid \bar{\xi}^{k}=\bar{z}^{k}}} g_{F}^{k+1}\left(\bar{x}^{k+1}, \bar{\xi}^{k+1}\right) \mid x^{k+1} \in K_{F}^{k+1}\left(\bar{x}^{k}, \bar{z}^{k}\right)\right\}, \\
k=1, \ldots, M-1
\end{gathered}
$$


depends (for every $\bar{\xi}^{k}$ ) on the conditional distribution function $F^{\xi^{k+1} \mid \bar{\xi}^{k}=\bar{x}^{k}}$ determined also for every value $\bar{\xi}^{k}=\bar{z}^{k}$ by $F^{\varepsilon}, k=1, \ldots, M-1$. However, it follows from this analysis, that decomposed problems (for every value of parameters and every $k$ ) are completely determined by the distribution function $F^{\varepsilon}$. Consequently, the system $F$ is determined by the distributions functions $F^{\xi^{1}}, F^{\varepsilon}$. If $F^{\varepsilon}, F^{\xi^{1}}$ are replaced by another $s$-dimensional distribution functions $G^{\varepsilon}, G^{\xi^{1}}$ then we obtain instead of the system $F$ another system

$$
G=\left\{G^{\xi^{1}}\left(z^{1}\right), G^{\xi^{k} \mid \bar{\xi}^{k-1}}\left(z^{k} \mid \bar{z}^{k-1}\right), k=2, \ldots, M\right\}
$$

and a new multistage stochastic programming problem. We denote its optimal value by the symbol $\varphi(G)$.

Furthermore, the following inequality has been proven in Kaňková (2002) (see also Kaňková, 2005) for every $x^{1} \in X^{1}$ :

$$
\begin{aligned}
& \mathrm{E}_{F^{\xi^{1}}} g_{F}^{1}\left(x^{1}, \xi^{1}\right)-\mathrm{E}_{G^{\xi^{1}}} g_{G}^{1}\left(x^{1}, \xi^{1}\right) \mid \leq \\
& \left|\mathrm{E}_{F^{\xi^{1}}} \inf _{x^{2} \in K_{F}^{2}\left(x^{1}, \xi^{1}\right)} \mathrm{E}_{F^{\xi^{2} \mid \xi^{1}}} g_{F}^{2}\left(\bar{x}^{2}, \bar{\xi}^{2}\right)-\mathrm{E}_{G^{\xi^{1}}} \inf _{x^{2} \in K_{F}^{2}\left(x^{1}, \xi^{1}\right)} \mathrm{E}_{F^{\xi^{2} \mid \xi^{1}}} g_{F}^{2}\left(\bar{x}^{2}, \bar{\xi}^{2}\right)\right|+ \\
& \mid \mathrm{E}_{G^{\xi^{1}}} \inf _{x^{2} \in K_{F}^{2}\left(x^{1}, \xi^{1}\right)} \mathrm{E} \inf _{F^{\xi^{2} \mid \xi^{1}}} \inf _{x^{3} \in K_{F}^{3}\left(\bar{x}^{2}, \bar{\xi}^{2}\right)} \mathrm{E}_{F^{\xi^{3} \mid \bar{\xi}^{2}}} g_{F}^{3}\left(\bar{x}^{3}, \bar{\xi}^{3}\right)- \\
& \mathrm{E}_{G^{\xi^{1}}} \inf _{x^{2} \in K_{G}^{2}\left(x^{1}, \xi^{1}\right)} \mathrm{E}_{G^{\xi^{2} \mid \xi^{1}}} \inf _{x^{3} \in K_{F}^{3}\left(\bar{x}^{2}, \bar{\xi}^{2}\right)} \mathrm{E}_{F^{\xi^{3} \mid \xi^{2}}} g_{F}^{3}\left(\bar{x}^{3}, \bar{\xi}^{3}\right) \mid+ \\
& \text {. } \\
& \mid \mathrm{E}_{G^{\xi^{1}}} \inf _{x^{2} \in K_{G}^{2}\left(x^{1}, \xi^{1}\right)} \cdots \cdots \inf _{x^{M-1} \in K_{G}^{M-1}\left(\bar{x}^{M-2}, \bar{\xi}^{M-2}\right)} \mathrm{E}_{G^{\xi^{M-1} \mid \bar{\xi}^{M-2}}} \\
& \inf _{x^{M} \in K_{F}^{M}\left(\bar{x}^{M-1}, \bar{\xi}^{M-1}\right)} \mathrm{E}_{F^{\xi^{M} \xi^{M-1}}} g_{F}^{M}\left(\bar{x}^{M}, \bar{\xi}^{M}\right)- \\
& \mathrm{E}_{G^{\xi^{1}}} \inf _{x^{2} \in K_{G}^{2}\left(x^{1}, \xi^{1}\right)} \cdots \cdots \inf _{x_{G}^{M-1} \in K_{G}^{M-1}\left(\bar{x}^{M-2}, \bar{\xi}^{M-2}\right)} \mathrm{E}_{G^{\left.\xi^{M-1}\right|_{\xi^{M-2}}}} \\
& \inf _{x^{M} \in K_{G}^{M}\left(\bar{x}^{M-1}, \bar{\xi}^{M-1}\right)} \mathrm{E}_{G^{\xi^{\xi_{I} \xi^{M-1}}}} g_{G}^{M}\left(\overline{\boldsymbol{x}}^{M}, \bar{\xi}^{M}\right) \mid
\end{aligned}
$$

According to the last relations we can see that to evaluate the value $|\varphi(F)-\varphi(G)|$ it can be useful to investigate

$$
\begin{aligned}
& \mid \inf _{x^{k+1} \in K_{F}^{k+1}\left(\bar{x}^{k}, \bar{\xi}^{k}\right)} \mathrm{E}_{F^{\left.\xi^{k+1}\right|^{k}}} g_{F}^{k+1}\left(\bar{x}^{k+1}, \bar{\xi}^{k+1}\right)- \\
& \quad \inf _{x^{k+1} \in K_{G}^{k+1}\left(\bar{x}^{1}, \bar{\xi}^{1}\right)} \mathrm{E}_{G^{\xi^{k+12}||^{k}}} g_{F}^{k+1}\left(\bar{x}^{k+1}, \bar{\xi}^{k+1}\right) \mid, \quad k=1, \ldots, M-1 .
\end{aligned}
$$


However, it follows from the last relations that to evaluate the value (9) the wellknown results achieved for one-stage problems can be employed with $F^{\xi^{k+1} \mid \bar{\xi}^{k}=\bar{z}^{k}}$, $G^{\xi^{k+1} \mid \bar{\xi}^{k}=\bar{z}^{k}}$ determined by $F^{\varepsilon}, G^{\varepsilon}$. To this end, it is necessary to find the assumptions under which (for every available values $\bar{x}^{k}, \bar{\xi}^{k}, K_{F}^{k+1}\left(\bar{x}^{k}, \bar{\xi}^{k}\right), K_{G}^{k+1}\left(\bar{x}^{k}, \bar{\xi}^{k}\right)$ are nonempty sets and, furthermore, to find the assumptions under which $\mathrm{E}_{F^{\xi^{k+1}} \bar{\xi}^{k}}$ $g_{F}^{k+1}\left(\bar{x}^{k+1}, \bar{\xi}^{k+1}\right)$ are finite Lipschitz functions (for more details see e.g. Kaňková Houda (2002); Kaňková - Houda, (2006a)).

\section{Auxiliary Assertions}

To recall some former results from one stage optimization theory, let $\bar{g}_{i}(x), i=1, \ldots, s$ be functions defined on $R^{n}, v=\left(v_{1}, \ldots, v_{s}\right)$ be $s$-dimensional random vector with distribution functions $G^{v}$ and one-dimensional marginal distribution functions $G_{i}^{v}, i=1, \ldots, s ; \quad \alpha_{i} \in\langle 0,1\rangle, i=1, \ldots, s, \bar{\alpha}=\left(\alpha_{1}, \ldots, \alpha_{s}\right)$. We define the sets $X_{F^{\varepsilon}}, X_{G^{v}}$ by the relations

$$
\begin{aligned}
& X_{F^{\varepsilon}}=X_{F^{\varepsilon}}(\bar{\alpha})=\bigcap_{i=1}^{s}\left\{x \in X: \bar{g}_{i}(x) \leq k_{F_{i}^{\varepsilon}}\left(\alpha_{i}\right)\right\}, \\
& X_{G^{v}}=X_{G^{v}}(\bar{\alpha})=\bigcap_{i=1}^{s}\left\{x \in X: \bar{g}_{i}(x) \leq k_{G_{i}^{v}}\left(\alpha_{i}\right)\right\} .
\end{aligned}
$$

( $k_{G_{i}^{v}}\left(\alpha_{i}\right), i=1, \ldots, s$ denotes the corresponding quantiles.)

Lemma 1. [Kaňková, 2007] Let $X_{F^{\varepsilon}}, X_{G^{v}}, X \subset R^{n}$ be nonempty, compact sets, $g_{0}$ be a uniformly continuous function defined on $X \times R^{s} ; X_{F^{\varepsilon}}, X_{G^{v}} \subset X$. If, moreover, for every $x \in X$ a finite $\mathrm{E}_{F^{\varepsilon}} g_{0}(x, \varepsilon), \mathrm{E}_{G^{v}} g_{0}(x, v)$ exist, then

$$
\begin{aligned}
& \left.\left|\inf _{F^{\varepsilon}} \mathrm{E}_{0}(x, \varepsilon)\right| x \in X_{F^{\varepsilon}}\right\}-\inf \left\{\mathrm{E}_{G^{v}} g_{0}(x, v) \mid x \in X_{G^{v}}\right\} \mid \leq \\
& \left|\inf _{X_{F^{\varepsilon}}} \mathrm{E}_{F^{\varepsilon}} g_{0}(x, \varepsilon)-\inf _{X_{F^{\varepsilon}}} \mathrm{E}_{G^{v}} g_{0}(x, v)\right|+\left|\inf _{X_{F^{\varepsilon}}} \mathrm{E}_{G^{v}} g_{0}(x, v)-\inf _{X_{G^{v}}} \mathrm{E}_{G^{v}} g_{0}(x, v)\right| .
\end{aligned}
$$

Evidently, it follows from Lemma 1 that if there exists $H_{1}, H_{2} \geq 0$ such that

$$
\begin{aligned}
& \left|\inf _{X_{F^{\varepsilon}}} \mathrm{E}_{F^{\varepsilon}} g_{0}(x, \varepsilon)-\inf _{X_{F^{\varepsilon}}} \mathrm{E}_{G^{v}} g_{0}(x, v)\right| \leq H_{1}, \\
& \left|\inf _{X_{F^{\varepsilon}}} \mathrm{E}_{G^{v}} g_{0}(x, v)-\inf _{X_{G^{v}}} \mathrm{E}_{G^{v}} g_{0}(x, v)\right| \leq H_{2},
\end{aligned}
$$

then $\left|\inf _{X_{F^{\varepsilon}}} \mathrm{E}_{F^{\varepsilon}} g_{0}(x, \varepsilon)-\inf _{X_{G^{v}}} \mathrm{E}_{G v} g_{0}(x, v)\right| \leq H_{1}+H_{2}$. 
Lemma 2. [Kaňková, 2007] Let $P_{F_{i}^{\varepsilon}}, i=1, \ldots, s$ be absolutely continuous (with respect to the Lebesgue measure on $R^{1}$ ) probability measures, (we denote by $f_{F_{i}^{\varepsilon}}$ the corresponding probability densities). If for $i \in\{1, \ldots, s\}$ there exist constants $\delta_{1}, \vartheta_{F^{\varepsilon}}(\bar{\alpha})>0$ such that $f_{F_{i}^{\varepsilon}}\left(z_{i}\right) \geq \vartheta_{F^{\varepsilon}}(\bar{\alpha})$ for $\left|z_{i}-k_{F_{i}^{\varepsilon}}\left(\alpha_{i}\right)\right| \leq 2 \delta_{1}$,

$$
\left|F_{i}^{\varepsilon}\left(z_{i}\right)-G_{i}^{v}\left(z_{i}\right)\right| \leq \delta, \quad \delta<\delta_{1} \vartheta_{F^{\varepsilon}}(\bar{\alpha}) \quad \text { for } \quad\left|z_{i}-k_{F_{i}^{\varepsilon}}\left(\alpha_{i}\right)\right| \leq \delta_{1},
$$

then $k_{G_{i}^{v}}\left(\alpha_{i}\right) \in\left\langle k_{F_{i}^{\varepsilon}}\left(\alpha_{i}\right)-\frac{\delta}{\vartheta_{F^{\varepsilon}}(\bar{\alpha})}, k_{F_{i}^{\varepsilon}}\left(\alpha_{i}\right)+\frac{\delta}{\vartheta_{F^{\varepsilon}}(\bar{\alpha})}\right\rangle$ and, moreover,

$$
\begin{aligned}
X_{G^{v}}(\bar{\alpha}+\bar{\delta}) & \subset X_{F^{\varepsilon}}(\bar{\alpha}) \subset X_{G^{v}}(\bar{\alpha}-\bar{\delta}), \\
X_{F^{\varepsilon}}(\bar{\alpha}+\bar{\delta}) & \subset X_{G^{v}}(\bar{\alpha}) \subset X_{F^{\varepsilon}}(\bar{\alpha}-\bar{\delta}), \quad \bar{\delta}=(\delta, \ldots, \delta) .
\end{aligned}
$$

The following assertion follows immediately from the assertion of Lemma 2.

Corollary 1.

If the assumptions of Lemma 2 are fulfilled, $k_{F^{\varepsilon}}(\bar{\alpha})=\left(k_{F_{1}^{\varepsilon}}\left(\alpha_{1}\right) \ldots, k_{F_{s}^{\varepsilon}}\left(\alpha_{s}\right)\right)$, $k_{G^{v}}(\bar{\alpha})=\left(k_{G_{1}^{v}}\left(\alpha_{1}\right) \ldots, k_{G_{s}^{v}}\left(\alpha_{s}\right)\right)$, then

$$
\left\|k_{F^{\varepsilon}}(\bar{\alpha})-k_{G^{v}}(\bar{\alpha})\right\| \leq \frac{s \delta}{\vartheta_{F^{\varepsilon}}(\bar{\alpha})} .
$$

Evidently, the assertion of Lemma 1 "decomposes" (from the mathematical point of view) the stability of one-stage stochastic programming problems to the problems with constraints depending on the "underlying" probability measure and to the problems with a probability measure in the operator of mathematical expectation only. Lemma 2 and Corollary 1 can be useful for the investigation of "stability" of the constraints sets or equivalently the corresponding multifunctions.

To investigate the stability of the problems in which probability measure appears in the operator of mathematical expectation we employ the Wasserstein metric $d_{W_{1}}\left(F^{\varepsilon}, G^{v}\right):=d_{W_{1}}\left(P_{F^{\varepsilon}}, P_{G^{v}}\right), P_{F^{\varepsilon}}, P_{G^{v}}$ are probability measures corresponding to the distribution functions $F^{\varepsilon}, G^{v}$. To this end let

$$
M\left(R^{s}\right)=\left\{P \in P\left(R^{s}\right): \int_{R^{s}}\|z\| P(d z)<\infty\right\},
$$

$P\left(R^{s}\right)$ denotes the set of all Borel probability measures on $R^{s}, s \geq 1,\|\cdot\|$ denotes a suitable norm in $R^{s}$. If we set

$$
d_{W_{1}}\left(F^{\varepsilon}, G^{v}\right)=\inf \left\{\int_{R^{s} \times R^{s}}\|z-z\| \kappa(d z \times d z): \kappa \in D\left(P_{F^{\varepsilon}}, P_{G^{v}}\right), \varepsilon, v \in M\left(R^{s}\right)\right\}
$$

then the Wasserstein metric will be completely determined by the norm $\|\cdot\|$ (for more details see Rachev, (1991) and Vallender, (1973)). We denote by 
$d_{W_{1}}\left(P_{F^{\varepsilon}}, P_{G^{v}}\right):=d_{W_{1}}^{1}\left(P_{F^{\varepsilon}}, P_{G^{v}}\right)$ if $\|\cdot\|$ is $L_{1}$ norm and $d_{W_{1}}\left(P_{F^{\varepsilon}}, P_{G^{v}}\right):=d_{W_{1}}^{2}\left(P_{F^{\varepsilon}}, P_{G^{v}}\right)$ if $\|\cdot\|$ is $L_{2}$ norm. $\left(D\left(P_{F^{\varepsilon}}, P_{G^{v}}\right)\right.$ is the set of those probability measures in $P\left(R^{s} \times R^{s}\right)$ whose marginal distribution are $P_{F^{\varepsilon}}$ and $P_{G^{v}}$.)

Lemma 3. [Kaňková - Houda, 2002, 2006a] Let $\left(P_{F^{\varepsilon}}, P_{G^{v}}\right) \in M\left(R^{s}\right)$. If for every $x \in X, g_{0}(x, z)$ is a Lipschitz (with respect to $L_{2}$ norm) function of $z \in R^{s}, z=\left(z_{1}, \ldots, z_{s}\right)$, the Lipschitz constant $L$ is not depending on $x \in X$. If, moreover, for every $x \in X$ a finite $\mathrm{E}_{F^{\varepsilon}} g_{0}(x, \varepsilon), \mathrm{E}_{G^{v}} g_{0}(x, v)$ exist, then

a) $\left|\mathrm{E}_{F^{\varepsilon}} g_{0}(x, \xi)-\mathrm{E}_{G^{v}} g_{0}(x, v)\right| \leq L d_{W_{1}}^{2}\left(P_{F^{\varepsilon}}, P_{G^{v}}\right)$,

b) $\left|\mathrm{E}_{F^{\varepsilon}} g_{0}(x, \varepsilon)-\mathrm{E}_{G^{v}} g_{0}(x, v)\right| \leq L \sum_{i=1}^{s} \int_{-\infty}^{+\infty}\left|F_{i}^{\varepsilon}\left(z_{i}\right)-G_{i}^{v}\left(z_{i}\right)\right| d z_{i} \quad$ for $\quad x \in X$.

The assertion a. (based on the $L_{2}$ norm) is only a little generalized well-known result of Römisch - Schulz (1993) (see also Kan̆ková - Houda, 2002). The assertion b. (based on the $L_{1}$ norm) has been proven on Kaňková - Houda (2006a). To obtain the last assertion, the results of Valander (1973) have been employed. Evidently, the bound determined by the assertion a. is suitable for a theoretical investigation, while, the bound introduced by the assertion $b$. is more acceptable from the numerical point of view.

\section{Discussion and Conclusion}

It follows from the relations (5) and (8) that to introduce an equivalent "classical" multistage problem to the problem defined by (1) and (2), first, it is necessary to determine the value of the quantiles $k_{F_{i}^{\varepsilon}}\left(\alpha_{i}\right), i=1, \ldots, s$. Evidently, this is relatively easy in the case when $F^{\varepsilon}$ is known. In the case when the values of the quantiles have to be estimated from the empirical distribution functions, then the results presented in Serfling (1980) can be employed to estimate an error of this approximation. However, if we apply the results of the former section to the multistage problems, then a "quality" of the approximation depends, furthermore, on the $H$ (in the assumption A.1) and $g_{i}^{k+1}, i=1, \ldots, s, k+1, \ldots, M-1$ (the relation 4). Consequently, we have to be very careful by a construction of approximative solution schemes. Some results about approximation constraints set can be found in Kaňková (1996). However, moreover, solving multistage problem we have to state the assumptions under which the constraints sets $K_{F}^{k+1}$ are nonempty. This problem is not yet completely solved (for more details see e.g. Birge - Louveaus, (1997)).

Lemma 3 introduces the stability results for one-stage stochastic programming problems in which probability measure appears in mathematical expectation while the constraints set is "deterministic". Applying, this results to the multistage case we can employee the approach of Kaňková - Šmíd (2004). However, in this case, we have to 
modify this approach with respect to constraints set depending on the probability measure. Moreover, to verify the assumption on the functions $g_{F}^{k}$ it can be more complicated in this case. To this end the results of Kaňková (1998), Kaňková - Šmíd (2004) can be employed. To apply the assertion b. of Lemma 3 to the case of empirical estimates we can employ new results of Kaňková - Houda (2006a, 2006b) and based on empirical processes. (for more details see e.g. Shorack - Wellner, 1986).

Consequently, theoretically it is possible to construct approximate solution schemes with the former determined approximation error in the case of deterministic approximate solution scheme; and with exponential rate of the convergence in the case when empirical measure replaces the theoretical one. However, to present the corresponding constructions is over the possibility of this paper.

\section{References}

[1] BIRGE, J. R.; LOUVEAUX, F. (1997). Introduction to Stochastic Programming. Berlin, Springer-Verlag, 1997.

[2] BIRGE, J. R. (1988). An L-Shaped Method Computer Code for Multistage Stochastic Linear Programs. In Ermoliev, Y. and Wets, R. J. B. (eds.). Numerical Techniques for Stochastic Optimization Problems. Berlin : Springer-Verlag, 1988, pp. 255-272.

[3] DUPAČOVÁ, J. (1995). Multistage Stochastic Programs: the State-of-the-Art and Selected Bibliography. Kybernetika, 1995, vol. 31, no. 2, pp. 151-174.

[4] DUPAČOVÁ, J.; HURT, J.; ŠTĚPÁN, J. (2002). Stochastic Modelling in Economics and Finance. Dordrecht : Kluwer, 2002.

[5] DUPAČOVÁ, J.; POPELA, P. (2005). Melt Control: Charge Optimization via Stochastic Programming. In Wallace, S. W.; Ziemba, W. T (eds.) (2005). Applications of Stochastic Programming. Philadelphia, Society for Industrial and Applied Mathematics / Mathematical Programming Society, 2005, pp. 277-298.

[6] CHOVANEC, P. (2004). Multistage Stochastic Programming Problems Application to Unemployment Problem and Restructuralization (Diploma thesis). Prague : MFF UK, 2004.

[7] ERMOLIEV, Y.; WETS, R. J. B. (eds.) (1988). Numerical Technique for Stochastic Optimization. Berlin : Springer, 1988.

[8] FRAUENDORFER, K.; SCHÜRLE, M. (2000). Term Structure in Multistage Stochastic Programming: Estimation and Approximation. Annals of Operations Research, 2000, vol. 100, no. 1-4, pp. 189-209.

[9] KAŇKOVÁ, V. (1996). A Note on Multifunction in Stochastic Programming. In Marti, K.; Kall, P. (eds.). Stochastic Programming Methods and Technical Applications. Berlin : Springer, 1996.

[10] KAŇKOVÁ, V. (1998). A Note on Multistage Stochastic Programming. In Proceedings 11th joint Czech-Germany-Slovak Conference. Liberec : University of Technology, pp. 45-52. 
[11] KAŇKOVÁ, V. (2002). A Remark on the Analysis of Multistage Stochastic Programs: Markov dependence. Zeitschrift für Angewandte Mathematik und Mechanik, 2002, vol. 82, no. 11-12, pp. 781-793.

[12] KAŇKOVÁ, V. (2005). Multistage Stochastic Decision and Economic Processes. Acta Oeconomica Pragensia, 2005, vol. 13, no. 1, pp. 119-127.

[13] KAŇKOVÁ, V. (2007). Multistage Stochastic Programming Problems; Stability and Approximation. In Waldmann, K.-H.; Stocker, U. M. (eds.). Operations Research Proceedings 2006, Berlin : Springer, 2007, pp. 595-600.

[14] KAŇKOVÁ, V.; HOUDA, M. (2002). A Note on Quantitative Stability and Empirical Estimates in Stochastic Programming. In Leopold-Wildburger, U; Rendl, F.; Wäscher, G. (eds.). Operations Research Proceedings 2002. Berlin : Springer-Verlag, 2003, pp. 413-418.

[15] KAŇKOVÁ, V.; HOUDA, M. (2006a). Empirical Estimates in Stochastic Programming. In Hušková, M.; Janžura, M. (eds.). Proceedings of Prague Stochastics 2006. Prague : Matfyzpress, 2006, pp. 426-436.

[16] KAŇKOVÁ, V.; HOUDA, M. (2006b). Dependent Samples in Empirical Estimation of Stochastic Programming Problems. Austrian Journal of Statistics, 2006, vol. 35, no. 2-3, pp. 271-279.

[17] KAŇKOVÁ, V.; CHOVANEC, P. (2006). Unemployment Problem via Multistage Stochastic Programming. In Pekár, J.; Lukáčik, M. (eds.). Proceedings of Quantitative methods in Economics (Multiple Criteria Decision making XIII). Bratislava, The Slovak Society for Operations Research / University of Economics in Bratislava, 2006, pp. 69-76.

[18] KAŇKOVÁ, V.; ŠMíD, M. (2004). A Remark on Approximation in Multistage Stochastic Programming; Markov Dependence. Kybernetika, 2004, vol. 40, no. 5, pp. 625-638.

[19] KING, A. J. (1988). Stochastic Programming Problems: Examples from the Literature. In Ermoliev, Y.; Wets, R. J.-B. (eds.). Numerical Techniques for Stochastic Optimization Problems. Berlin : Springer, 1988, pp. 543-567.

[20] KUHN, D. (2005). Generalized Bounds for Convex Multistage Stochastic Programs. Lectures Notes in Economics and Mathematical Systems 548. Berlin : Springer-Verlag, 2005.

[21] NOWAK, M.; RÖMISCH, W. (2000). Stochastic Lagrangian Relaxation Applied to Power Scheduling in Hydro-Termal System Under Uncertainty. Annals of Operation Research, 2000. Vol. 100, pp. 251-272.

[22] PFLUG G. Ch. (2001). Scenario Tree Generation for Multiperiod Financial Optimization by Optimal Discretization. Mathematical Programming, 2001, vol. 89, serie B89, pp. 251-271.

[23] POWEL, W. B.; TOPAlOGLU, H. (2003). Stochastic Programming in Transportation and Logistics. In Ruszczyński, A.; Shapiro, A. (eds.). Stochastic Programming, Handbooks in Operations Research and Management Science, vol. 10. Amsterdam : Elsevier, pp. 555-636.

[24] PRÉKOPA, A. (1995). Stochastic Programming. Budapest : Akadémiai Kiadó and Dordrecht, Kluwer, 1995. 
[25] RACHEV, S. T. (1991). Probability Metrics and the Stability of Stochastic Models. New York : Wiley, 1991.

[26] RÖMISCH, W.; SCHULZ, R. (1993). Stability of Solutions for Stochastic Programs with Complete Recourse. Mathematics of Operation Research, 1993, vol.18, no. 3, pp. 590-609.

[27] RUSZCZYŃSKI, A. (2003). Decomposition Methods. In Ruszczyński, A.; Shapiro, A. (eds.). Stochastic Programming, Handbooks in Operations Research and Management Science, vol. 10. Amsterdam : Elsevier, 2003, pp. 141-209.

[28] SERFLING, J. R. (1980). Approximation Theorems of Mathematical Statistics. New York : Wiley, 1980.

[29] SHORACK, G. R.; WELLNER, J. A. (1986). Empirical Processes with Applications to Statistics. New York : Wiley, 1986.

[30] ŠMíD, M. (2004). On Approximation of Stochastic Programming Problems. (Doctoral Thesis). Prague : MFF UK, 2004.

[31] VALLENDER, S. S. (1973). Calculation of the Wasserstein Distance between Probability Distribution on the Line. Theory of Probability and its Applications, 1973, vol. 18, no. 4, pp. 784-786.

[32] WALlACE, S. W.; FLETEN, S. E. (2003). Stochastic Programming Models in Energy. In Ruszczyński, A.; Shapiro, A. (eds.). Stochastic Programming, Handbooks in Operations Research and Management Science, Amsterdam : Elsevier, 2003, vol. 10, pp. 637-677.

[33] WALlACE, S. W; ZIEMBA, W. T (eds.) (2005). Applications of Stochastic Programming. Philadelphia : Society for Industrial and Applied Mathematics / Mathematical Programming Society, 2005. 


\title{
Autoregresní posloupnosti v úlohách vícestupňového stochastického programování
}

\section{Vlasta Kaňková}

\begin{abstract}
Abstrakt
Ekonomické a sociální děje se vyvíjejí v čase pod vlivem náhodných faktorů. Konečný průběh procesu však většinou závisí i na rozhodnutích, které provozovatel během vývoje volí $\mathrm{v}$ mezích stanovených podmínkami problému. Teorie vícestupňového stochastického programování, stochastického dynamického programování, řízených Markovových procesů a v poslední době rychle se rozvíjející teorie empirických procesů patří $\mathrm{k}$ technikám, které provozovatel může využít pro kvalitní rozhodnutí. Práce je zaměřena na problematiku vícestupňového stochastického programování $\mathrm{s}$ individuálním pravděpodobnostním omezením a náhodným faktorem splňujícím podmínky obecně nelineární autoregresní posloupnosti.
\end{abstract}

Klíčová slova: ekonomické procesy; vícestupňové stochastické programování; autoregresní posloupnosti; individuální pravděpodobnostní omezení.

\section{Multistage Stochastic Programming via Autoregressive Sequences}

\begin{abstract}
Economic activities developing over time are very often influenced simultaneously by a random factor (modeled mostly by a stochastic process) and a "decision" parameter (that has to be chosen according to economic possibilities). Theory of multistage stochastic programming, controlled Markov processes as well as empirical processes can be employed to treat the economic processes. We focus on the multistage stochastic problems with the individual probability constraints and random element following an autoregressive (generally) nonlinear sequence.
\end{abstract}

Key words: economic processes; multistage stochastic programming; autoregressive sequences, individual probability constraints.

JEL classification: C44. 